\title{
A pilot study on the impact of recreational diving on the airway patency depending on a diver's age Piotr Siermontowski ${ }_{\mathrm{A}, \mathrm{B}, \mathrm{D}, \mathrm{E}, \mathrm{F}}$, Robert Koktysz ${ }_{\mathrm{C}}$, Tomasz Wojtowicz ${ }_{\mathrm{B}, \mathrm{E}}$
}

${ }^{1}$ Maritime \& Hyperbaric Medicine Department Military Medicine Institute Gdynia.

${ }^{2}$ Clinical Pathology Department Military Medicine Institute Warszawa.

\begin{abstract}
Amateur diving is becoming a more and more popular form of recreation for people of all ages (often even those over fifty years old) in Poland.

The aim of this preliminary study was to determine whether practising amateur diving affects the subjects and, if so, how it influences the basic parameters of the respiratory system.

The study was conducted during an 11-day cruise on the Mediterranean Sea combined with diving cycles. An experimental group consisted of 14 subjects from 21 to 50 years old. In total there were 124 individual dives made in a depth range from 12 to 43 meters. Each time before entering the water and immediately after the dive a PEF test was performed. The results were recorded in the daily dives card. All the results are summarized in the table and statistical analysis has been made.

As a result of the study, depending on the depth a statistically significant negative correlation found between the age of the divers and the value of PEF after diving could be seen, as well as a statistically significant negative correlation between the age of the diver and the value of PEF and the time the dive was carried out.
\end{abstract}

keywords: recreational diving, PEF, age

\section{Introduction}

Amateur diving is becoming an increasingly popular form of recreation for people of all ages (often even those over te age of fifty) in Poland. Diving is treated in the same way as other forms of physical activity e.g. jogging, swimming, or cycling. If people who take part in this form of physical activity were subjected to the proper healthcare checks [7], then physical recreation such as diving would give the same positive health effects as other forms of recreation.

In the literature long-term effects of diving are reported, especially in forms of aeration lung disorders or changes in clinical spirometry $[2,6,11,12,13]$, however, those studies focused on professional divers who carried out numerous and/or deep dives, often with the use of breathing mixtures. There is no description of the influence of authentic dives for tourists on the respiratory system flow capacity performed on a group of subjects with a relatively wide age range. The most popular reports were made during simulated dives in pressure chambers. Those studies were conducted on professional divers in a narrow age group $[12,13,16,17]$.

It has encouraged us to undertake a pilot study during actual dives involving a research group with a wide age range.
The aim of the study:

The aim of the study was to determine the initial direction of changes in the respiratory system flow capacity after amateur dives in different age groups.

\section{Materials and methods:}

The study was conducted during an 11-day cruise combined with a series of dives. An experimental group consisted of 14 respondents in an age range from 21 to 50 years old, and was made up of 11 men and 3 women. All participants were healthy, none of them suffered from COPD or other respiratory diseases. Five men were smokers. The age of the respondents correlated with their diving experience. The subjects' took part in their first dives between 20 and 25 year of age.

Measurement assumptions: the value of PEF is dependent on the time of the day - it is lowest in the morning, between 4 and 6 am, and highest in the afternoon, between 4 and $6 \mathrm{pm}[1,4,5]$. The typical daily alternation is less than $20 \%[1,4,5]$.

The correct PEF value for any particular patients depends on sex, age, height and exertions made. Approximately the range of the norm is within $\pm 20 \%$ of the predicted value $[4,5,8]$. In this way the astronomical times of the dives measured and presented below were selected. In total 124 individual dives were performed at a depth of 12 to 43 meters with an exposure length of 12 to 120 minutes (calculated from the beginning of the 
Tab. 1. The daily dives card

\begin{tabular}{|c|c|c|c|c|c|c|c|c|c|c|}
\hline $\mathrm{Lp}$ & Name & Signature & $\begin{array}{c}\text { D iving } \\
\text { degree }\end{array}$ & $\begin{array}{c}\text { Preassure/ } \\
\text { cylind er } \\
\text { capacity }\end{array}$ & automaton & $\begin{array}{l}\text { Immersion } \\
\text { time }\end{array}$ & $\begin{array}{l}\text { Time of } \\
\text { coming } \\
\text { back to } \\
\text { the sur- } \\
\text { face }\end{array}$ & $\begin{array}{l}\text { Depth in } \\
\text { meters }\end{array}$ & $\begin{array}{l}\text { PEF be- } \\
\text { fore }\end{array}$ & PEF after \\
\hline \multicolumn{11}{|l|}{1.} \\
\hline \multicolumn{11}{|l|}{2.} \\
\hline \multicolumn{11}{|l|}{3.} \\
\hline \multicolumn{11}{|l|}{4.} \\
\hline \multicolumn{11}{|l|}{5.} \\
\hline \multicolumn{11}{|l|}{6.} \\
\hline \multicolumn{11}{|l|}{7.} \\
\hline \multicolumn{11}{|l|}{8.} \\
\hline \multicolumn{11}{|l|}{9.} \\
\hline 10 & & & & & & & & & & \\
\hline
\end{tabular}

immersion until resurfacing). Each time before entering the water and immediately after the dive there measurements of peak expiratory flow (PEF) were carried out twice within one minute on each of the participants. The results were written down in the daily dives card (Table 1). PEF is one of the spirometric parameters specifying the maximum flow of air through the airways during the maximum expiration intensity expressed in $1 / \mathrm{min}$. It was decided to measure this parameter due to the fact that there is a simple way to measure it by means of a simple, handy, and readily available device. Two peak-flow meters made by Vitalograph asmaPlan+ with a measurement range of 50 to $800 \mathrm{l} / \mathrm{min}$ were used. The results

tab. 2 . (the average of two measurements) were written down in the daily dives card.

For the purpose of further analysis the group was divided into two sub groups, group 1 - less than 40 years old (8) and group 2 - over 40 years old (4 people). All the information about the divers, dive profiles and the results of the measurements were collected in the table and statistically analyzed by means of Mann - Whitney $\mathrm{U}$ test.

\section{The results:}

Data on the dives made by the respondents is presented in table 2

\begin{tabular}{|l|l|l|l|l|l|l|}
\hline group & Group number & Number of expositions & \multicolumn{2}{|c|}{ Diving time } & \multicolumn{2}{c|}{ Depth } \\
\hline & & & Average & Standard devation & Average & Standard devation \\
\hline 2 & 4 & 44 & 42,3 & 6,923 & 30,16 & 6,555 \\
\hline 1 & 8 & 80 & 40,14 & 17,96 & 25,48 & 8,522 \\
\hline
\end{tabular}

Data on the results of the PEF measurements obtained is shown in table 3

tab. 3 .
The correlations between the measurement values, the age and the conditions of the dive are shown in table 4

\begin{tabular}{|l|l|l|l|l|l|l|}
\hline group & Group number & Number of expositions & \multicolumn{2}{|c|}{ PEF before diving } & \multicolumn{2}{c|}{ PEF after diving } \\
\hline & & & Average & Standard devation & Average & Standard devation \\
\hline 2 & 4 & 44 & 49,1 & 7,966 & 51,73 & 10,09 \\
\hline 1 & 8 & 80 & 53,05 & 10,24 & 48,53 & 9 \\
\hline
\end{tabular}


tab. 4.

\begin{tabular}{|l|l|l|}
\hline & \multicolumn{1}{|c|}{ Before diving } & After diving \\
\hline Age &,$- 025(\mathrm{p}=, 785)$ &, $\mathbf{2 7 3}(\mathbf{p}=\mathbf{0 0 2})$ \\
\hline Diving time &, $118(\mathrm{p}=, 192)$ & $\mathbf{, 1 9 2}(\mathbf{p}=\mathbf{0 3 2})$ \\
\hline Depth &,$- 086(\mathrm{p}=, 341)$ &,$- 006(\mathrm{p}=, 946)$ \\
\hline
\end{tabular}

The statistical significance of the group's comparisons is presented in table 5

Tab. 5

\begin{tabular}{|l|l|l|l|l|}
\hline & $\mathrm{p}$ & Gr. 1 & Gr. 2 & $\mathrm{p}$ \\
\hline age & $\mathbf{0 , 0 0 4}$ & $\mathbf{8 0}$ & $\mathbf{4 4}$ & $\mathbf{0 , 0 0 6}$ \\
\hline $\begin{array}{l}\text { PEF befo- } \\
\text { re diving }\end{array}$ & $\mathbf{0 , 0 0 0}$ & $\mathbf{8 0}$ & $\mathbf{4 4}$ & $\mathbf{0 , 0 0 0}$ \\
\hline $\begin{array}{l}\text { PEF after } \\
\text { diving }\end{array}$ & $\mathbf{0 , 0 0 0}$ & $\mathbf{8 0}$ & $\mathbf{4 4}$ & $\mathbf{0 , 0 0 0}$ \\
\hline $\begin{array}{l}\text { Diving } \\
\text { time }\end{array}$ & 0,216 & 80 & 44 & 0,217 \\
\hline Depth & 0,974 & 80 & 44 & 0,977 \\
\hline
\end{tabular}

As a result of the study, a statistically significant negative correlation between the age of the diver and the PEF value after diving can be seen, as well as a statistically significant, negative correlation between the diver's age and the PEF value and the diving time.

\section{Discussion of the results:}

It was found that longer periods of practicing recreational diving is beneficial for improving the efficiency of the respiratory system, monitored by means of PEF index. "Improvement" is directly proportional to diving experience, and in terms of our experiment it is also proportional to the diver's age.

The "Improvement" state of the respiratory system competence measured by means of PEF in our research shows a strong statistical significance, despite the actual aging of the respiratory system, linked to the diver's age.

The research mentioned in the beginning of the article showed the deterioration of spirometric indicators in professional divers. We assume, therefore, that practicing diving as a form of recreation may produce the opposite effect and provide a positive impact on the state of the respiratory tract. The morphological chan- ges connected with biomorphic processes in the lungs that are presented as the decline of the interalveolar septum (leading to senile emphysema) and especially the loss of elastic fibers, reduces the lungs elasticity [10]. It is not excluded that the necessity of more strenuous breathing due to the breathing agent with increased density, $[10,15]$ in this case encouraged alveoli expansion.

Better results in the PEV study may show evidence of airway patency improvement, particularly higher caliber [10]. This improvement in older participants with a greater amount of diving experience can be primarily connected with the work of the sympathetic nervous system causing the enlargement of the airways lumen, or blocking the action of the parasympathetic system $[9,10]$. The authors anathematised a possible greater "tolerance" of the trachea and larger bronchi walls to elevate oxygen partial pressures in longer dives because, when assuming the reaction of the bronchial walls to hyperbaric oxygen in the shape of the mucous membrane oedema and the contraction $[9,14]$ after diving, we would not observe the improvement of the parameters researched by means of PEV but their deterioration.

Due to the uneven number of the test groups as well as comprehensive exposure reproducibility which the respondents were assayed the results cannot be fully reliable, however, they show a clear trend. [3]

Our study pertained only to the impact of a single dive on a single spirometric indicator, however, it has shown a marked improvement which will lead to further research.

\section{Conclusions:}

1. It is advisable to conduct a further study on the impact of shallow recreational dives on breathing parameters. 2. It is possible to use the impact of recreational diving as a method of physical therapy to improve the functional status of the respiratory tract, especially for people who previously practiced diving. 


\section{References:}

1. Andziulis A., Gocentas A., Jascaniniene N., Jaszczanin J., Juozulynas A., Radzijewska M. Respiratory function dynamics in individuals with increased motor activity during standard exercise testing. Fiziol. Zh. 2005;51(4):86-95.

2. Bouhuys A., Beck G. J. Large lungs in divers? J. Appl. Physio Respir. Environ. Exerc. Physiol. 1979; 47(5):1136-1137.

3. Clanton T. L., Dixon G. F., Drake J., Gadek J. E. Effects of swim training on lung volumes and inspiratory muscle conditioning. J. Appl. Physiol.1987; 62(1): $39-46$.

4. Godfrey S., Kamburoff P.L., Nairn J.R. Spirometry, lung volumes and airway resistance in normal children aged 5 to 18 years. Br. J. Dis. Chest. 1970; 64(1):15-24.

5. Gregg A. J., Nunn I. New regression equations for predicting peak expiratory flow in adults. BMJ. 1989; 22;298(6680):1068-1070.

6. Konarski M., Klos R., Nitsch-Osuch A., Korzeniewski K., Prokop E. Lung function in divers. Adv. Exp. Med. Biol. 2013;788:221-7. doi: 10.1007/978-94007-6627-3_32.

7. Medical examinations of sport scuba divers. Davies E. red., Undersea \& Hyperbaric Med. Soc. 1986. 8. Roca J., Burgos F., Sunyer J., Saez M., Chinn S., Anto J. M., Rodriguez-Roisin R., Quanjer P. H., Nowak D., Burney P. References values for forced spirometry for the Group of the European Community Respiratory Health Survey. Eur. Respir. J.1998; 11(6): 1354-1362. 9. Swanney M. P., Ruppel G., Enright P. L., Pedersen O. F., Crapo R. O., Miller M. R., Jensen R. L., Falaschetti E., Schouten J. P., Hankinson J. L., Stocks, J., Quanjer P. H. Using the lower limit of normal for the FEV1/FVC ratio reduces the misclassification of airway obstruction. Thorax. 2008; 63(12): 1046-1051.
10. The Mechanical Basis of Respiration Peters R.M. (red) Little, Brown \& Co. Boston 1969.

11. Thorsen E., Segadal K., Kambestad B.K., Gulsvik A. Diver's lung function: small airways disease? Br. J. Ind. Med. 1990, 47(8): 519-523.

12. Thorsen E., Segadal K., Kambestad B.K., Gulsvik A. A longitudinal study of pulmonary function after deep saturation dives. Proceedings, XVIIth Annual Meeting of EUBS on Diving and Hyperbaric Medicine, Heraklion, Crete, Greece; 29 September -3 October 199, s. 49.

13. Thorsen E., Gulsvik A. One year follow up of pulmonary function after two saturation dives to pressures of 0.25 and 3.7 MPa. UHMS Annual Scientific Meeting 1994; Undersea Hyperbaric Med. 1994, Suppl. 21., Abstract No. 24: 25.

14. Tetzlaff K., Friege L., Reuter M., Haber J., Mutzbauer T., Neubauer B. Expiratory flow limitation in compressed air divers and oxygen divers. Eur. Respir. J. 1998; 12(4): 895-899.

15. Vail E. G. Hyperbaric respiratory mechanics. Aerosp. Med. 1971; 42(9), 975-979.

16. Watt S.J. Lung function in commercial air and saturation divers. UHMS Annual Scientific Meeting 1994; Undersea Hyperbaric Med. 1994, Suppl. 21., Abstract No. 23: 25.

17. Watt S.J. Effect of commercial diving on ventilatory function. Br. J. Ind. Med. 1985; 42(1): 59-62.

\section{Correspondence address:}

Piotr Siermontowski

Maritime \& Hyperbaric Medicine Departament Military Institute of Medicine 81-103

ul. Grudzińskiego 4

Gdynia 3 box 18 